\title{
Author Correction: Targeted pharmacological therapy restores $\beta$-cell function for diabetes remission
}

Stephan Sachs, Aimée Bastidas-Ponce, Sophie Tritschler, Mostafa Bakhti iD, Anika Böttcher, Miguel A. Sánchez-Garrido, Marta Tarquis-Medina, Maximilian Kleinert, Katrin Fischer, Sigrid Jall, Alexandra Harger, Erik Bader, Sara Roscioni, Siegfried Ussar (D), Annette Feuchtinger, Burcak Yesildag, Aparna Neelakandhan, Christine B. Jensen, Marion Cornu, Bin Yang, Brian Finan (D), Richard D. DiMarchi, Matthias H. Tschöp (D), Fabian J. Theis (D), Susanna M. Hofmann (D), Timo D. Müller (D) and Heiko Lickert (D)

Correction to: Nature Metabolism https://doi.org/10.1038/s42255-020-0171-3, published online 20 February 2020.

In the version of this article initially published, in Fig. 7c, in the 'Day 25' panels, the 'GLP-1-oestrogen' image mistakenly duplicated the 'PEG-insulin' image. The error has been corrected in the HTML and PDF versions of the article.
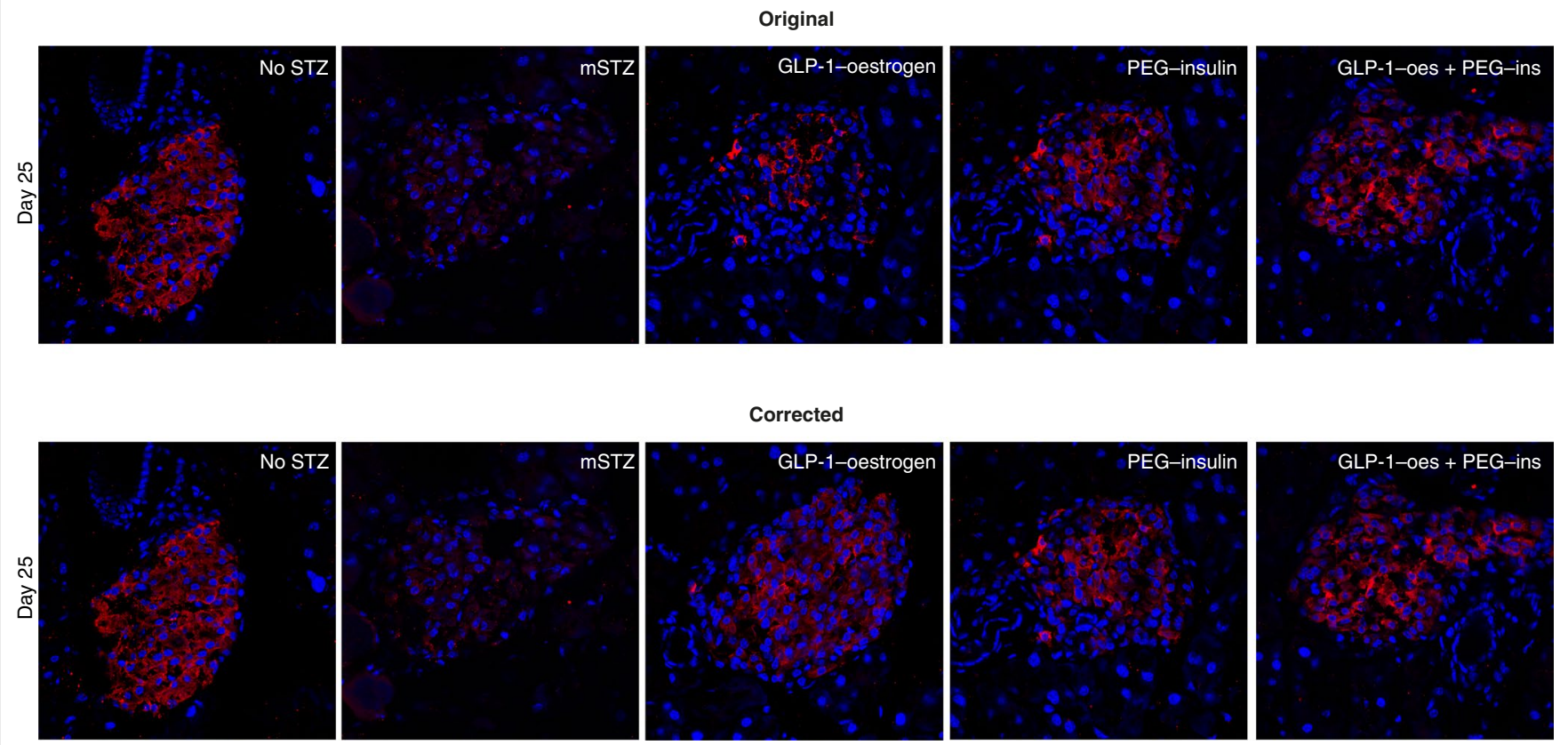

Fig 7c | Original and corrected Day 25 panels.

Published online: 14 April 2020

https://doi.org/10.1038/s42255-020-0201-1

(C) The Author(s), under exclusive licence to Springer Nature Limited 2020 